\title{
Classroom Interaction and Language Output
}

\author{
Qiaoying Wang (Corresponding Author) \\ Foreign Language Department, Bijie University \\ Bijie, Guizhou, China \\ E-mail: Qiaokingyx@yahoo.com.cn
}

Carolyn D. Castro

Department of Reading, ESL, and Linguistics, Montgomery College

51 Mannakee Street, Rockville, MD, USA

Tel: 1-240-567-4176_E-mail: Carolyn.Castro@montgomerycollege.edu

\begin{abstract}
This study investigates the effects of classroom interactions between a) students and students and b) students and teachers on the learning of English passivization by L1 Chinese adult learners of English as a foreign language during the language input and output treatments. In phase 1, both groups were asked to read and underline the input material. After the materials were collected, the participants were required to produce the first reconstruction. After having been exposed to the same input material again, the participants produced the reconstruction the second time. In phase 2, participants wrote a short passage on a given topic and were presented a sample of the writing provided by the participating teacher. The results of this study suggest that classroom interaction and the language output may trigger learners to notice the target form and have a positive effect on improving the learning of a foreign language.
\end{abstract}

Keywords: English passive voice, Classroom interaction, Language input and output

\section{Introduction}

The efficacy of language teaching and learning has been the subject of research for many years, and most of the researchers have focused their studies on second language acquisition. From Krashen's Comprehensible Input (1985) to Swain's Comprehensible Output (1995) and Long's Interaction Hypothesis (1996), such research has made great contributions to second language acquisition. The difference between second language acquisition and foreign language learning lies in that the second language acquirers have opportunities to practice the target language outside the classroom, while foreign language learners only have limited opportunities to learn English in the classroom. This observation prompted the present study, which explores the efficiency and effectiveness of classroom teaching on learning EFL. Producing language output has been regarded as a very important process in language acquisition and learning. However, it has also been noted that not all language output can promote language acquisition and learning (e.g., cite studies). Only under certain circumstances does the output contribute to improving the target language acquisition and learning (Swain, 1985). Given this, the present study focuses on the roles of the classroom interactions in promoting language output when learners learn a certain target language form as a foreign language.

\subsection{The input and output hypothesis}

The Input Hypothesis claims that language input (listening comprehension and reading) is important in the language program and that fluency in speaking or writing in a second language will naturally happen after learners have built up sufficient competence through comprehending input. Many studies (Tanaka,1991; Yamazaki,1991) on the nature of input revealed that input facilitates the acquisition of words in the target language, but does not aid the acquisition of certain syntactic structures (Ellis, 1994).

It is agreed that comprehensive input is essential but not sufficient in promoting second language acquisition, and that output can push learners to notice the gap between their interlanguage and target language (Swain, 1985). The Output Hypothesis proposed by Swain (1985) argued that language output may trigger the learners to pay attention to the target linguistic form in order to express their intended meaning. The noticing function of the Output Hypothesis posits that learners may notice the gap in their IL knowledge in an attempt to produce the target language to prompt them to solve their linguistic deficiency in ways that are appropriate in a given context. Recent research implies that attention does work in SLA. For example, Schmidt stated that a connection exists 
between learning and attention. He further explains that noticing, which requires learner focus, is an important part of the learning process (Schmidt, 2001).

Prior research has explored the role of consciousness-raising and focus on form (Doughty 2001; Doughty \& Williams, 1998; Long, 1996; Rutherford \& Sharwood Smith, 1985), and showed that visual input enhancement draws learners' attention to form in the written input, such as bolding, capitalizing, and underlining, which are formatting techniques that draw learners' attention to the target form.

\subsection{The Interaction Hypothesis and classroom interactions}

Long's Interaction Hypothesis (1996) posits that interaction focuses on the 'negotiation for meaning'. The frequency of occurrence of the target form brings about salience, negative feedback, and input modifications to increase comprehensibility and content predictability. These processes induce 'noticing' of new forms, new form-meaning connections, gaps in interlanguage, and mismatch between input and output. Long (1996) noted that interaction facilitates comprehension and acquisition of semantically contingent speech and negotiation for meaning. Long stresses the importance of the interactional modifications that occur in negotiating meaning. In other words, interactive input is more important than non-interactive input (Ellis, 1994).

Classroom interactional tasks that stimulate negotiation for meaning may turn out to be those among several useful language-learning activities, for they may be the easiest ways to facilitate a learner's focus on form. Classroom interactional tasks often contain learner classroom participation, group work, teacher talk, role plays, etc. The communicative language teaching theory reveals that communication and interaction are the purpose of language learning (Richards \& Rodgers, 1986), and previous studies on communicative language teaching (Hymes, 1972; Nunan, 1991) show that interaction facilitates the learning of language functions as well as of target language forms.

Numerous studies have examined the effect of the quantity and quality of learner classroom participation on their L2 achievement, but the results have not been conclusive. For example, Seliger (1977) and Strong (1984) found positive effects, while Allwright's study (1980) yielded opposite results. With regard to the quality of learner participation in class, tasks and group work are involved, Long (1980) and Newton (1991) showed in their studies that the two-way interactional tasks result in increased negotiation of meaning. Furthermore, the study by Long, Adams, McLean, and Castanos (1976) found that students working in small groups produce better language production compared to learners working individually. This suggests that group work offers more opportunities for learners to produce language. Wong-Fillmore (1982) demonstrated that interactions between a teacher and individual students, as well as between and among learners influence L2 learning. Her study suggested that classroom interaction can affect L2 learning, but it does not shed any light on how specific linguistic features are learned.

\subsection{Empirical studies on language output}

Specific linguistic features were involved in previous empirical studies conducted by Izumi, Bigelow, Fujiwara and Fearnow (1999) on the noticing function of output. Their studies found that the extended opportunities to produce output and receive input can prompt learners' SLA. In a later study, Izumi (2002) examined whether output and visual input enhancement, in isolation or in combination, promoted noticing and learning of an L2 grammatical form. However, Izumi's previous research did not allow the teachers of the participating classes to teach the target form or answer any questions about the target form and did not allow the participants to discuss the target form with other people. Drawing from Izumi's studies $(1999,2002)$, this present study investigates the effects of classroom interactions in language input and output in promoting foreign language students' noticing of the gap between their interlanguage and the target language and the learning of the target language. The present study addresses the following research questions.

1) Do classroom interactions trigger the learners to notice the target form?

2) Do classroom interactions during input and output treatments help prompt the learning of the target form?

\section{Method}

\subsection{Target form}

English passive voice was chosen as the target form in this study because it is difficult for Chinese students to master the use of the English passive voice. In other words, the grammatical structure of Chinese impedes the learning of the English passive voice. First, "Chinese is topic-prominent in that topic and comment make up the canonical structure, whereas English is subject-prominent in the sense that subject and predicate are the 
major constituents of sentential structure" (Li \& Thompson, 1976). Therefore, it is not common to use the passive voice in Chinese. For example:

Chinese: Zhebenshu yijing kanwanle.

English: This book already have read.

Second, although Chinese passive and English passive constructions are similar in syntax, in Chinese passive, the word bei is used to express the passive without any morphological change in the verb, while in the English passive, the verb stem changes morphologically to the past participial form. Therefore, Chinese students often make mistakes when using the passive voice.

\subsection{Participants}

Forty students from two intact classes in the English Department of a university in Guizhou, China, participated in the present study; their ages ranged from 17 to 25 years old. All of the 40 students have learned English for six years. None of them had lived or stayed in an L1 English environment. The participants had learned the passive in the secondary schools, but they have yet to fully grasp the use of this structure. For instance, they produced the following sentences, which show traces of their L1 Chinese structure:

\section{(1) My homework has not finished.}

\section{(2) Your mother is ill. She needs to take care of.}

The selection of the participants was determined using a test of English passive voice administered by English faculty before the treatment. This served as a screening test for the participants. Those who obtained a score of 60 were excluded from participating, while those who scored below 60 were selected. A total of 28 out of 53 students met the requirements and were selected as the participants in this study. The ages of the 28 participants vary from 19 to 25 years old. All of them have studied English for six years. None of them lived or stayed in an L1 English environment.

The 28 participants were divided into two groups (14 participants in each group). One group received the treatment, while the other group did not. A pretest was administered to ensure that the two groups were comparable before treatment, and posttests were administered to compare the two groups after the treatments.

Three written testing measures were used in the pretest and posttests to assess the participants' knowledge of the English passive voice before and after the treatments. The pretest and posttests had similar formats and involved tasks on sentence transformation, grammaticality judgment, and translation, which aimed to test the students' receptive knowledge of the passive as well as production of this target form.

\subsection{Research Design}

The pretest-posttests design of this study draws from Izumi, et al. (1999). However, one important difference from Izumi's experimental design is that both the treatment and non-treatment groups in the present study received language input and were asked to produce output. Although both groups were asked to generate passive forms, only the treatment group (TG) underwent classroom interactional activities. This means that learners in this group were allowed to ask the teacher questions about the target form, and discussed and learned the target form in groups, while the non-treatment group (NTG) did not.

The treatment comprised two phases, with two tasks in each phase. The treatment began immediately after the formation of the two groups.

\subsection{Procedures of Treatment}

The materials used in Phase 1 were a monitored article from a newsletter about an e-classroom (Appendix A). The article was divided into two parts because it was too long. In the article, there were many sentences in the passive voice which were needed in the research. Part A was used as the material for Task A, Phase 1, and Part B was the material for Task B, Phase 2.

The participants in the treatment group were given the opportunity to produce the written output so that they might notice a gap in their written production before and after the treatment. The non-treatment group was completed the comprehension questions based on the given passages. Before the treatment began, both groups engaged in activities which familiarized them with the treatment procedures.

In Task A, Phase 1, the participants in both groups were asked to read the passage and underline the words, or phrases that they thought were particularly necessary for their subsequent written production (10 mins.). Neither group was allowed to ask the teacher questions about the target form or to discuss it with other people. The teacher did not teach the target form in order to get a clear comparison between the two groups at the very 
beginning. After the participants finished reading and underlining what they believed to be relevant structures in the text, the material was collected. Then, both groups were given fifteen minutes to accomplish the required tasks on the answer sheets given by the researcher. The treatment group completed the reconstruction task (Appendix B), while the non-treatment group completed the reading comprehension test (Appendix C). After fifteen minutes, the answer sheets were collected. Then, both groups were exposed to the same input material for the second time and were given five minutes to reread the material, after which the material was collected. Both groups were then given fifteen minutes to accomplish the same required task as they did at the first time, i.e., the treatment group completed the second reconstruction task, and the non-treatment group answered the second reading comprehension test. After that, the answer sheets of both groups were collected again. Table 1 shows the treatment procedures.

Task B involved the same set of procedures as Task A. The difference is that the participants in the treatment group were encouraged to ask the teacher questions about the target form in the input material and to discuss it with their classmates, while those in the non-treatment group were not allowed to ask their teachers any questions or discuss the target form among themselves. That is to say, in Task B, the treatment group engaged in classroom interaction, while the other group did not. Classroom interaction involved the teachers answering questions about the target form, and teaching the target form if the students seemed confused about its use. This treatment phase was then followed by posttest 1 (See Appendix D).

Although the reconstruction tasks offered the opportunity to the participating students of the treatment group to produce the target form, these tasks were controlled and were not creative. In order to provide the participants of the treatment group with the opportunity for producing the target form naturally, Phase 2 was designed, so that the participants may use the target form freely by writing a short passage on a certain topic. In order to compare the performance of the two groups, both groups were asked to write a short passage on the topic "School Library" using the passive voice where possible. Before the participants wrote the required passage, the teacher took all the participants to the school library to give them a better idea of what to write about. The students could take notes of the information about the library. After returning to the classroom, the students were given an hour to write a passage on the school library that they had just visited. Participants in the treatment group were asked to work in groups, whereas those in the non-treatment group worked individually. For easy calculation, the number of the passive sentences was limited to ten in the passage written by the students. According to the Output Hypothesis, text underlining, note-taking and reconstruction tasks in both phases involve internal processes that would be triggered by each stage of the instructional sequence (Izumi, et al., 1999). These tasks are devices to draw the learners' attention to the target form. The reconstruction task is "a unique 'linguistic problem-solving task" (Izumi, 2002, p. 251). It integrates meaning with forms and maximizes the equivalence between the learners' output and the target input to promote direct comparisons between the students IL-output and TL- input forms (Izumi, 2002).

With regard to the classroom interactional activities in Phases 1 and 2, only the treatment group was involved in these activities. The students in this group asked questions about the input text on the target form after they finished the reading and underlining tasks. The teacher did not initiate the discussion or the questions about the target form, but answered any question the students raised on the input text and the target form. The teacher even taught the target form when the students from the treatment group expected the teacher to teach it. The participants in the treatment group were presented the chance to work in groups where they could help each other with the tasks. They discussed the tasks and the target form together and learned it from each other.

\subsection{Testing Instruments}

Three written testing measures were employed in the three tests (one pretest and the two posttests) to assess the participants' knowledge of the English passive voice before and after the treatments. The pretest and the two posttests are the same format except the test items were substituted by using different words or phrases. Sentence transformation, grammaticality judgment test and translation test were included in the pre-and posttests.

\subsubsection{Grammaticality judgment test}

The grammaticality judgment test aimed at testing the students' receptive knowledge. Ten sentences with the target form were written on the test sheet, of which, eight were incorrect and two were correct. The participants were asked to decide whether the given sentences are correct or incorrect and they had to correct the sentences that they determine to be incorrect. The test was completed in 30 minutes.

\subsubsection{Transformation and translation tests}

Transformation and translation tests were employed to measure the students' production of the target form. This was different from earlier studies carried out by Izumi, et al. (1999) who adapted it from Doughty (1988), 
Doughty and Williams (1998), and Hyltenstam (1984). Instead of a picture-cued sentence completion test, a transformation test asked the students to change ten active sentences into the passive voice and a translation test asked the students to translate into English a short passage consisting of ten Chinese sentences created for this study using the passive voice if possible.

\subsection{Scoring and Analyses}

The data for analysis included the learners' outputs from the underlining and reconstruction tasks in Phase One, the written production task in Phase Two, and the scores from the pretest and the two posttests. All the test data were scored by giving one point for a correct response and no point for an incorrect response. The use of the incorrect verb forms of the passive voice was not awarded any point even though the rest of the sentence was correct. As for the reconstruction scores, only the second reconstruction done by the students was scored because some students did not return their first reconstructions

\subsubsection{Grammaticality judgment test scoring}

In scoring the grammaticality judgment test, one point is gained when a participant correctly identifies whether or not a given sentence is grammatical or not. Raw scores were then converted to percentages.

\subsubsection{Underlining scoring}

The learners' scores in the underlining task were obtained by counting the total number (Total number=16) of the verb forms of the passive voice that the participants underlined and converting the number into the corresponding percentage. One participant in the treatment group and two in the non-treatment group were excluded for the analysis of underlining scoring because they underlined all the words in the passage.

\subsubsection{Production scoring}

Target-like use analysis and interlanguage analysis were employed in scoring the production task. Deciding on whether a participant's sentence production was correct or incorrect mainly depended on the correct use of the passive voice and its verb forms. Incorrect use of the tenses, singular or plural forms of the verb 'be' and incorrect morphology (e.g., taked* for taken) were also taken to be incorrect. The scores were also converted into percentages.

\subsubsection{Test scoring}

The pre-test and two post-tests followed the same format. The maximum score was 30 points. All of the test data were scored by giving one point for a correct response and no point for an incorrect response. In other words, each test item was scored one point if the use of the passive voice and the verb form of the passive voice in a sentence was correct. Test scores were obtained by dividing the total number of correct scores by the total number of applicable items. Thus, the test scores were presented in percentage form.

\section{Results}

\subsection{Results of the underlining task}

Table 2 presents the scores of the two groups in the underlining tasks A and B in Phase 1. As shown, there was a significant increase in the number of correctly identified passive forms from Task A to Task B: from $46 \%$ to $95 \%$ for the treatment group (TG) and $42 \%$ to $74 \%$ for the non-treatment group (NTG). This suggests that both groups showed greater awareness with respect to their noticing of the target form of the passive voice. It is noted, too, that there is little difference between the two groups in Task A when neither group was involved in classroom interactions. In Task B, however, learners in the TG who were involved in classroom interactions outperformed the non-treatment group: $95 \%$ vs. $74 \%$. This finding suggests that classroom interactions may trigger foreign language learners to notice the target form.

\subsection{Results of the reconstruction task}

Table 3 shows the results of the reconstruction Tasks A and B. The two groups were comparable in their scores in Task A (53\% and 52\%), but there is a significant difference in the percentage of correct target forms supplied by the two groups in Task B. For the TG, the percentage of correct target forms supplied increased significantly from Task A (53\%) to Task B (92\%). This may be due to classroom interactional activities involved in the tasks because the participants of the TG learned the target form by asking the teacher questions about the passive or learned from each other. For the NTG who produced some output, there is also a significant increase in the percentage of correct usage of the target form from Task A (52\%) to Task B (88\%). This implies that classroom interaction and language output are helpful to English language learning. In short, both groups performed significantly better in Task B, but the TG did not outperform the NTG in the reconstruction task. 


\subsection{Results of the production task}

Production scores by the TG and the NTG in Phase 2 are shown in Table 4. As revealed, both groups gained an increase in their scores from Task A to Task B. Similar to the previous results shown in Table 1 and Table 2, both groups obtained comparable scores in Task A (61\% and 59\%) and both groups scored significantly higher in Task B (83\% and 77\%). This result may suggest that classroom interaction has a positive effect on language production. The groups' performance in the production task is very similar to their performance in the reconstruction task, in that, while both groups showed great improvement from Task A to Task B, there is no significant difference in their scores in Task B.

\subsection{Results of pretest and posttests}

Table 5 shows the results of the pretest and the two posttests. First, we find that both groups scored the same in the pretest $(40 \%)$, which means that the two groups are comparable at the start before treatment in terms of their knowledge of the target form, the passive voice. Second, Table 5 also reveals that both groups have a significant increase in their scores from the pretest to the first posttest (64\% and 54\%), as well as to second posttest (73\% and $64 \%)$. However, there is no marked difference between the two groups' performance in the pretest or posttests.

\section{Discussion}

In this study, there are three major findings that contain four aspects: underlining, reconstruction, production, and scores in the pretest and posttests. First, the learners' scores in underlining tasks A and B in Phase One show that the TG, which was involved in output production and classroom interactions, outperformed the NTG, who produced only output. This implies that classroom interactions may trigger foreign language learners to notice the target form. Second, in terms of the reconstruction and production tasks, the scores obtained by the two groups for Task A and Task B do not show a considerable influence of classroom interactions on foreign language learning, but the scores do show that classroom interactions have a facilitative effect on learning the target form from Task A to Task B. This finding supports the results of the study conducted by Wong-Fillmore (1982) on the effect of classroom interactions on L2. Third, language output was shown to have the potential to boost foreign language learning.

In relation to the first research question that asked whether classroom interactions trigger the learners to notice the target form, there is evidence in the study leading to a positive answer. The results in Table 2 show that classroom interactions may promote noticing of the target form. In Task A, neither group was involved in classroom interactions. They just read the passage and underlined the words or phrases they considered useful for the subsequent reconstruction tasks; consequently, the results for both groups are similar. In contrast to the results of Task A, in Task B which involved classroom interactional activities, such as learner participation, task-based interaction, and small group work, the treatment group involved in classroom interaction and output production performed much better than the output only group, which suggests that classroom interactions may prompt learners to notice the target form. Ellis (1994) argued that "the interaction provides learners with opportunities to encounter input or to practice the target language. It also creates within the learners a 'state of receptivity', defined as "an active openness, a willingness to encounter the language and the culture" (Ellis, 1994, pp. 573-574). When the students asked the teacher questions, interaction between the teacher and learners transpired and the resulting teacher talk can attract the learner's attention and may be more facilitative of acquisition of the target form. Numerous studies by other researchers such as Seliger (1977), Strong (1984), Long (1989), etc. demonstrate that classroom interactions help in the acquisition of the L2, while this study shows that classroom interactions do help learners to notice and learn the target form of a foreign language.

Although the two groups obtained comparable scores in the Reconstruction and Production tasks both in Task A and Task B, it is noted that the learners in the NTG also performed well in the Underlining Task B, and that there is a significant increase in their scores from Task A to Task B. This finding implies that output may also trigger learners to notice the target form, a finding which is inconsistent with Izumi, et al.'s study (1999) on testing the noticing function of the Output Hypothesis. In his study, the output failed to draw L2 learner's attention to the target form. In the present study, however, the performance of the NTG in Task B suggests that output does trigger a foreign language learner to notice the target form. This may be due to the foreign language learner's sensitivity to the grammar of the target language. Another reason may be that language output with classroom interactions can promote language learning (Swain, 1985). In Izumi, et al. (1999), only the underlining task was involved in testing the noticing function of the Output Hypothesis, while his later study (2002), where visual input enhancement and note-taking were utilized, showed that output can make learners attend to the target form. Therefore, we may say that not all types of output result in noticing the target form among learners. It is only 
when the learners are required to notice the linguistic form of a target language can output promote the processes of noticing the target linguistic form.

With respect to the second research questions that asked whether classroom interactions during input and output treatments promote learning of the target form, the results do not show a difference between the TG that was involved in classroom interactions and the NTG that was not. In the reconstruction of Task A, the participants who engaged in classroom interaction performed much better than those without classroom interaction, but there was no difference in the performance of the two groups in Task B. On the contrary, both groups performed well in Tasks A and B in the reconstruction task. This finding may suggest that output, under certain circumstances "may provide language learners with ideal ground in which to encourage syntacticization and sensitization to language forms" (Izumi, 2003, p. 189).

However, classroom interactions do not significantly promote the learning of the target form. The findings in this study fail to show the superiority of the treatment group which was involved in classroom interactions over the non-treatment group which was not. The treatment group's small increase in scores as shown in Tables 3, 4 and 5 suggests that classroom interaction may have a positive effect on the learning of the target form. This finding is partially consistent with that discussed in Long (1980,) Newton (1991), Long, Adams, McLean and Castano (1976). Long's (1980) and Newton's (1991) studies showed that the two-way tasks result in increased negotiation of meaning and provide more opportunities for learners to produce the target form. Long, et al. (1976) found that students working in small groups produced high quality language, a finding that is not confirmed in the present study.

The results in the three tests on the acquisition issue show that the group conducting output and classroom interactions made progress from the pretest to both posttests, which may mean that the output produced by means of classroom interactions facilitated the learning of the target form. The performance of the non-treatment group in the three tests also confirms that output does promote the noticing and learning of a specific target linguistic form. Although the small difference between the two groups in the posttests indicates that not all circumstances of production may provide language learners with effective language learning opportunities, classroom interactions do have a positive effect on the learning of the target form. As for the obvious increase in the scores of the NTG in the two posttests, this may suggest that active awareness of the target language forms. Most Chinese English learners tend to focus on English syntactic forms when they learn English.

There are some limitations in this study and some of the issues need to be studied in the future. First, the results from this small-scale research may not be generalizable. Therefore, there is a need to conduct a larger-scale study to observe the effect of classroom interactions on learning target linguistic forms in a foreign language. Second, only a few tasks involving classroom interactions were used in this study. The effect of other tasks such as recast, teacher talk, turn-taking, etc., and their impact on learning the target language should be investigated because task-based language learning tends to make learners "produce more complex and more target-like language when they have come to plan their output" (Ellis, 1994, p. 596). Finally, there is a need to measure the durability of the learning of the target forms that were observed, and explore the effect of classroom interactions in long-term studies.

\section{Conclusion}

This study investigated the effects of classroom interactions among adult L1 Chinese learners of EFL, and between EFL students and teachers on the learning of English passive voice during language input and output treatments. The results of this study suggest that classroom interactions may trigger learners to notice the target form and have a positive effect on the learning of the target language. The results also confirmed that under certain circumstances (in this study, only when the learners are required to notice the linguistic form of the target language), output can promote learning and production of the target L2 form. This finding implies the need for EFL classroom pedagogy that is student-centered and offers more opportunities for language learners to produce the target language in meaningful contexts.

Since language output and classroom interactions have been shown to have a facilitative impact on language learning, EFL teachers should stimulate learners' interests and provide as many opportunities as possible for language learners to produce the target language by implementing various classroom interaction tasks. Classroom teaching that is learner-centered can provide more opportunities for EFL learners to produce and learn the target language.

\section{References}

Allwright, R. (1980). Turns, topics and tasks: Patterns of participation in language teaching and learning in Larsen-Freeman, D. (ed.), Discourse analysis in second language research (pp. 165-187). 
Doughty, C. (1988). The effect of instruction on the acquisition of relativization in English as a second language. Unpublished doctoral dissertation. University of Pennsylvania.

Doughty, C. (2001). Cognitive underpinnings of focus on form in Robinson, P. (ed.) Cognition and second language instruction (pp. 206-257). New York: Cambridge University Press.

Doughty, C., and Williams, J. (1998). Pedagogical choices in focus on form in Doughty C. and Williams, J. (eds.), Focus on form in classroom second language acquisition (pp. 197-262). New York: Cambridge University Press.

Ellis, R. (1994). The study of second language acquisition. Oxford: Oxford University Press.

Hyltenstam, K. (1984). The use of typological markedness conditions as predictors in second language acquisition: The case of pronominal copies in relative clauses in Andersen, R. (ed.), Second languages: A cross-linguistic perspective (pp. 39-58). Rowley, MA: Newbury House.

Hymes, D. (1972). On communicative Competence in J.B. Pride and J. Holmes (eds.). sociolinguistics, pp.269-293. Harmondsworth: Penguin.

Izumi, S., Bigelow, M., Fujiwara, M. \& Fearnow, S. (1999). Testing the output hypothesis: Effects of output on noticing and second language acquisition. Studies in Second Language Acquisition, 21(3), 421-452.

Izumi, S. (2002). Output, input enhancement, and the noticing hypothesis: An experimental study on ESL relativization. Studies in Second Language Acquisition, 24 (4), 541-577.

Izumi, S. (2003). Comprehension and production processes in second language learning: In search of the psycholinguistic rationale of the output hypothesis. Applied Linguistics, 24 (2), 168-196.

Krashen, S. (1985). The input hypothesis: Issues and implications. London: Longman.

Li, C. and Thompson, S. (1976). Subject and topic: A new typology of language in Li, C. (ed.) Subject and topic (pp. 457-489). New York: Academic Press.

Long, M., Adams, L., McLean, M. and Castanos, F. (1976). Doing things with words: Verbal interaction in lockstep and small group classroom situations in Fanselow, J. and Crymes, R. (eds.), in On TESOL '76 (pp. 137-153). Washington, DC: TESOL.

Long, M. (1980). Input, interaction, and second language acquisition. Unpublished doctoral dissertation. Los Angeles: University of California.

Long, M. (1989). Task, group, and task-group interactions. University of Hawaii Working Papers in ESL, 8, $1-26$.

Long, M. (1996). The role of the linguistic environment in second language acquisition in Ritchke, W.C. \& Bhatia, T.K. (eds.), Handbook of Language Acquisition. Second Language Acquisition (pp. 413-468). New York: Academic Press.

Newton, J. (1991). Negotiation: Negotiating what? Paper given at SEAMEO Conference on Language Acquisition and the Second/Foreign Language Classroom. Singapore: RELC

Nunan, D. (1991). Methods in second language classroom-oriented research: a critical review. Studies in Second Language Acquisition 13, 247-274.

Richards, J. and T. Rogers. (1986). Approaches and Methods in language teaching. Cambridge: Cambridge University Press.

Rutherford, W. and Sharwood Smith, M. (1985). Consciousness-raising and universal grammar. Applied Linguistics, 6, 274-282.

Schmidt, R. (2001). Attention in Robinson, P. (ed.) Cognition and second language instruction (pp. 3-32). New York: Cambridge University Press.

Seliger, H. (1977). Does practice make perfect? A study of the interaction patterns and L2 competence. Language Learning, 27, 263-278.

Strong, M. (1984). Integrative motivation: Cause or result of successful second language acquisition? Language Learning, 34, 1-14.

Swain, M. (1985). Communicative competence: Some roles of comprehensible input and comprehensible output in its development in Gass, S. and Madden, C. (eds.), Input in second language acquisition (pp. 235-256). Rowley, MA: Newbury House. 
Swain, M. (1995). Three functions of output in second language learning in Cook, G. and Seidelhofer, B. (eds.), Principle and practice in applied linguistics: Studies in honor of H.G. Widdowson (pp. 125-144). Oxford: Oxford University Press.

Tanaka, Y. (1991). Comprehension and L2 acquisition: The role of interaction. Unpublished paper. Tokyo: Temple University Japan.

Wong-Fillmore, L. (1982). Instructional language as linguistic input: Second language learning in classroom in Wilkinson, L.C. (ed.), Communicating in the classroom (pp. 283-296). New York: Academic Press.

Yamazaki, A. (1991). The effect of interaction on second language comprehension and acquisition. Unpublished paper. Tokyo: Temple University Japan.

\section{Appendix A: Sample of Input Materials for Task A and Task B in Phase 1 \\ Passage A: Mini E-Classroom}

\section{(Adapted from DLSU Newsette Balitang Aklatan Vol. 35, No. 7, July 2004)}

The mini E-classroom under the IMS is located on the second floor of the library building in De La Salle University Library. It had already been completed and was ready for use by the first week of July.

Because it has been designed for small classes, the room has a multi-media projector, nine computers for the students and one with a console for the faculty. Each computer is installed with Director MX (Macromedia), Front Page (for web designing), Microsoft XP, and the Net Support School (NSS) system. The room is strictly for the use of classes which are involved in the production of instructional materials using computer programs, doing on-line search, and using Integrated Virtual Learning Experience (IVLE). Reservation for its use is filed at the IMS counter located on the ground floor of the library building.

Teachers could easily watch, share or control the screen, keyboard or the mouse of their student's workstation by having a "thumbnail view". A discussion or chat box can be opened where the students could enter comments. This is ideal for conducting class forums.

These days, some training programs are being conducted in the mini E-classroom.

The goals and objectives that should be achieved are training the teachers to use the E-classroom properly and skillfully. The topics or contents to be covered are then determined. The corresponding visual aids and learning materials are also specified. The training design is usually done by the training staff of the organization and sometimes by outside consultants. The services of training consultants are usually availed of the companies for this purpose.

The training objectives of the training design are a critical element that should be written properly to be able to decide on the contents. The training implementation has been properly attended to by the teachers and the other faculty of the university.

(Continued)

\section{Appendix B: Reconstruction Exercise for Task A}

\section{Directions: Use the appropriate forms of the verbs given to fill in the blanks.}

(locate) on the second floor of the library building in De La Salle University Library. It (complete) and was ready for use by the first week of July, in 2004.

Designed for small classes, the room has a multi-media projector, nine computers for the students and one with a console for the faculty. Each computer (install) with Director MX (Macromedia), Front Page (for web designing), Microsoft XP, and the Net Support School (NSS) system. The room is strictly for the use of classes involved in the production of instructional materials using computer programs, doing on-line search, and using Integrated Virtual Learning Experience (IVLE). Reservation for its use (file) at the IMS counter located on the ground floor of the library building.

Teachers could easily watch, share or control the screen, keyboard or the mouse of their student's workstation by having a "thumbnail view". A discussion or chat box (can, open) where the students could enter comments. This is ideal for conducting class forums.

These days, some training programs (conduct) in the mini E-classroom. The goals and objectives that should be achieved are training the teachers to use the E-classroom properly and skillfully. The topics or contents (cover) are then determined. The corresponding visual aids and learning materials are also specified. The training design and the TNA are usually done) by the training staff of the 
organization and sometimes by outside consultants. The services of training consultants (usually, avail) of the companies for this purpose.

The training objectives of the training design are a critical element that (should, write) properly to be able to decide on the contents. So far the training implementation (properly, attend to) by the teachers and the other faculty of the university.

\section{Appendix C: Sample of the Test}

\section{Grammaticality Judgment Test (10 points)}

Directions: There are ten sentences in the following. Decide whether the given sentences are correct or incorrect and correct the sentences that you determine to be incorrect.

1. When this story was read a second time, the meaning was make clear.

2. As the image developed in Yeats' poem, the poem is filled with more alliteration.

3. He will struck by the car if he crosses the street.

4. Women have victimized for centuries.

5. The particular topic chosen by the instructor for study in his section of English must to approve by the Steering Committee.

6. Avoidance of such blunders should not consider a virtue for which the student is to be commended, any more than he would be praised for not wiping his hands on the tablecloth or polishing his shoes with guest towels.

7. Collaborative analytical determinations were utilized to assess the probable consequences of mechanical failure. [Start with "Analysts."]

8. The difference between restrictives and nonrestrictives can be also better approached through a study of the different contours.

9. In the next thirty-five years it is expected that there will be more engineering work to do than has been done in all of recorded history.

10. Trees on average sites are expected to be about twenty inches in diameter when they are eighty years old if they properly are manage since youth.

\section{Answer Key}

1. When this story was read a second time, the meaning was made clear.

2. As the image developed in Yeats' poem, the poem is filled with more alliteration.

3. He will be struck by the car if he crosses the street.

4. Women have been victimized for centuries.

5. The particular topic chosen by the instructor for study in his section of English writing must be approved by the Steering Committee.

6. Avoidance of such blunders should not be considered a virtue for which the student is to be commended, any more than he would be praised for not wiping his hands on the tablecloth or polishing his shoes with guest towels.

7. Collaborative analytical determinations were utilized to assess the probable consequences of mechanical failure. [Start with "Analysts."]

8. The difference between restrictives and nonrestrictives can be also better approached through a study of the different contours.

9. In the next thirty-five years it is expected that there will be more engineering work to do than has been done in all of recorded history.

10. Trees on average sites are expected to be about twenty inches in diameter when they are eighty years old if they are properly managed since youth.

\section{Transformation Test (10 points)}

\section{Directions: Change the active sentences in the following passage into the passive voice if possible.}

Our mistakes also increase our knowledge, if only because we have made a mistake, and we must find a way of correcting it. If we had not made the mistake in the first place, we might have had no reason to learn how things 
are done. As I wrote the first version of this essay, a few minor errors were made. As a result of my mistakes, since I did discover them, I have already learned a lot.

Not only human brain's continual bumbling has often made mistakes, but also Computer may make mistakes. However, it is quite different in that human beings, one might say, have emotions and desires and prejudices that mistakes are the result of them. In fact, fewer mistakes will mean that the stumbling of the human species will bring about fewer of those useful discoveries and inventions.

\section{Translation Test}

Directions: Translate the following passage from Chinese into English using the passive voice where possible.

他家最后被列为拆迁户之一，他家的老宅下半年就要被拆掉了。可是窗户是才刚漆过，墙壁也才新刷的， 房顶和门窗也才翻修过。去年又在后园里修建了一个鱼池, 前园又种了许多的花草。可这一切很快就要 不存在了, 他家所在的这片地区要修一座现在化的体育馆, 体育馆里将配备先进的体育设施, 另外还将 修建一条高速公路直接通向市中心。

His family was eventually listed as one of the relocatees. His old house will be knocked down in the next few months. The windows and the walls of the house have just been painted and the roofs, the doors and the windows have been renovated. Last year, in the back yard, a fishpond was built. In the front garden, a lot of flowers have been planted. But all of these will soon no longer exist. A modern stadium equipped with an advanced sports facilities will be constructed in this area. A highway leading directly downtown is planned to be built here, too.

Table 1. Treatment Sequence (Adapted from Izumi, 1999)

\begin{tabular}{|c|c|c|}
\hline Sequence & Activity & Time \\
\hline 1. & Pretest & 45 mins. \\
\hline 2. & $\begin{array}{l}\text { Treatment Phase } 1 \text {, Task A } \\
\text { Passage on Mini E-classroom (Part A) }\end{array}$ & 45 mins. \\
\hline 3. & $\begin{array}{l}\text { Treatment Phase 1, Task B } \\
\text { Passage on Mini E-classroom (Part B) }\end{array}$ & 45 mins. \\
\hline 4. & Posttest 1 & 45 mins. \\
\hline 5. & $\begin{array}{l}\text { Treatment Phase 2, Task A } \\
\text { Write a short passage on The School Library }\end{array}$ & $1 \mathrm{hr}$ \\
\hline 6. & $\begin{array}{l}\text { Treatment Phase 2, Task B } \\
\text { Rewrite the same passage }\end{array}$ & $1 \mathrm{hr}$. \\
\hline 7. & Posttest 2 & 40 mins. \\
\hline
\end{tabular}

Table 2. Underlining Scores for the TG and the NTG in Phase 1, Tasks A and B

\begin{tabular}{lcccc}
\hline \multicolumn{2}{c}{ Task A } & \multicolumn{2}{c}{ Task B } \\
\hline Group & $\begin{array}{c}\text { Total number } \\
\text { of the passive } \\
\text { voice in } \\
\text { Passage } \mathrm{A}\end{array}$ & $\begin{array}{c}\text { Mean } \% \text { of } \\
\text { the passive } \\
\text { underlined }\end{array}$ & $\begin{array}{c}\text { Total number } \\
\text { of the passive } \\
\text { voice in } \\
\text { Passage B }\end{array}$ & $\begin{array}{c}\text { Mean \% of } \\
\text { the passive } \\
\text { underlined }\end{array}$ \\
\hline TG $(\mathrm{n}=13)$ & 16 & 46 & 22 & \\
NTG $(\mathrm{n}=12)$ & 16 & 42 & 22 & 74 \\
\hline
\end{tabular}


Table 3. Reconstruction Scores for the TG and the NTG in Phase 1, Tasks A and B

\begin{tabular}{lclcc}
\hline Task A & \multicolumn{3}{c}{ Task B } \\
\hline Group & $\begin{array}{l}\text { Total number } \\
\text { of passive } \\
\text { sentences for } \\
\text { reconstruction }\end{array}$ & $\begin{array}{l}\text { Mean \% of } \\
\text { correct } \\
\text { passive } \\
\text { sentences }\end{array}$ & $\begin{array}{c}\text { Total number } \\
\text { of passive } \\
\text { sentences for } \\
\text { reconstruction }\end{array}$ & $\begin{array}{c}\text { Mean \% of } \\
\text { correct } \\
\text { passive } \\
\text { sentences }\end{array}$ \\
\hline TG $(\mathrm{n}=14)$ & 15 & 53 & 15 & 92 \\
NTG $(\mathrm{n}=14)$ & 15 & 52 & 15 & 88 \\
\hline
\end{tabular}

Table 4. Production Scores for the TG and the NTG in Phase 2, Tasks A and B

\begin{tabular}{ccc}
\hline Group & $\begin{array}{c}\text { Task A } \\
\text { Mean \% of } \\
\text { correct passive }\end{array}$ & $\begin{array}{c}\text { Task B } \\
\text { Mean \% of } \\
\text { correct passive }\end{array}$ \\
\hline TG $(\mathrm{n}=14)$ & 61 & 83 \\
NTG $(\mathrm{n}=14)$ & 59 & 77 \\
\hline
\end{tabular}

Table 5. Test Scores for the TG and the NTG

\begin{tabular}{lccc}
\hline Group & $\begin{array}{c}\text { Pretest Score } \\
\text { (Mean in \%) }\end{array}$ & $\begin{array}{c}\text { Posttest 1 Score } \\
\text { (Mean in \%) }\end{array}$ & $\begin{array}{c}\text { Posttest 2 Score } \\
\text { (Mean in \%) }\end{array}$ \\
\hline TG $(\mathrm{n}=14)$ & 40 & 64 & 73 \\
NTG $(\mathrm{n}=14)$ & 40 & 54 & 64 \\
\hline
\end{tabular}

